\title{
Global epidemiology of nonpolio enteroviruses causing severe neurological complications: A systematic review and meta- analysis
}

\author{
Sarika Suresh $^{1,2}$ @ | William D. Rawlinson, ${ }^{2,3,4}$ @ | Peter lan Andrews ${ }^{3,5}$ | \\ Sacha Stelzer-Braid ${ }^{2,3}$
}

${ }^{1}$ Melbourne Medical School, University of Melbourne, Parkville, Australia

${ }^{2}$ Virology Research Laboratory, Prince of Wales Hospital, Randwick, Australia

${ }^{3}$ School of Medical Sciences, and School of Women's and Children's Health, Faculty of Medicine, and School of Biotechnology and Biomolecular Sciences, Faculty of Science, University of New South Wales, Sydney, Australia

${ }^{4}$ Serology and Virology Division (SAViD), Microbiology NSW Health Pathology, Randwick, Australia

${ }^{5}$ Department of Paediatric Neurology, Sydney Children's Hospital, Randwick, Australia

Correspondence

Sacha Stelzer-Braid, Virology Research Laboratory, Level 3 Clinical Sciences Building, Prince of Wales Hospital, Randwick, Australia 2031.

Email: s.stelzer-braid@unsw.edu.au

\begin{abstract}
Summary
Enteroviruses are RNA viruses found as commensals in the human gut and respiratory system, which may cause a wide spectrum of disease. Enteroviruses may cause severe neurologic complications including acute flaccid paralysis (AFP) and encephalitis and are the most commonly diagnosed agents of viral meningitis. Outbreaks of more severe disease are often associated with particular genotypes, such as enterovirus-A71 causing rhombencephalitis and AFP. There are more than 300 described genotypes of human enterovirus, with overlaps in clinical phenotypes between genotypes, and uncertainty about which genotypes are more prevalent in neurological manifestations.
\end{abstract}

A systematic review of observational studies was conducted to evaluate the most prevalent enterovirus genotypes causing AFP, encephalitis, and meningitis. The genotyping methods and sampling sites were compiled as secondary outcomes. Sources included MEDLINE, Embase (publications until January 2019), and references selected from included studies. Meta-analyses using a random effects model were performed to calculate the pooled proportion of enterovirus genotypes in each disease.

Ninety-six publications met the eligibility criteria, comprising 3779 AFP cases, 1140 encephalitis cases, and 32810 meningitis cases. Enterovirus-A71 was most frequently associated with AFP (pooled proportion $0.12,95 \% \mathrm{Cl}, 0.05-0.20$ ) and encephalitis $(0.77,95 \% \mathrm{Cl}, 0.61-0.91)$. Echovirus $30(0.35,95 \% \mathrm{Cl}, 0.27-0.42)$ was the most predominant genotype in meningitis cases. Genotypes were most commonly determined using VP1 RT- reverse transcription-polymerase chain reaction, and most samples assessed were cerebrospinal fluid.

With the emergence of enteroviruses as an increasing cause of neurological diseases, surveillance and testing need to increase to identify the aetiology of the most common and most severe disorders.

KEYWORDS

acute flaccid paralysis, encephalitis, enterovirus, meningitis, systematic review

Abbreviations: EV, enterovirus; AFP, acute flaccid paralysis; CNS, central nervous system; NPEV, nonpolio enterovirus; EV-D68, enterovirus-D68; EV-A71, enterovirus-A71; RT-PCR, reverse transcription-polymerase chain reaction; 5'UTR, 5' untranslated region; PRISMA, Preferred Reporting Items for Systematic Reviews and Meta-Analysis; WHO, World Health Organisation; CEBM, Centre for Evidence-based Medicine; CDC, The Centre for Disease Control and Prevention; AFM, acute flaccid myelitis. 


\section{1 | INTRODUCTION}

Human enteroviruses (EVs) are a genus of the Picornaviridae family and responsible for a number of neurological conditions including acute flaccid paralysis (AFP), encephalitis, and meningitis. ${ }^{1}$ They are divided into four subgroups in humans based on their pathogenesis and host range: Enteroviruses $A$ through $D .^{2}$ Polioviruses are classified as part of the Enterovirus $C$ species and have a well-defined pathogenicity in the human central nervous system (CNS). However, due to the success of poliovirus vaccination programs, there has been nearglobal eradication of clinical poliomyelitis. ${ }^{3}$ The first nonpolio enterovirus (NPEV) was discovered in 1948 when Dalldorf et al inoculated newborn mice with faecal suspensions from suspected polio patients. ${ }^{4}$ The inoculation resulted in paralysis of the mice, and the causative agent differed from poliovirus. This initially unclassified virus was deemed the first member of the group A coxsackie viruses. Since then there have been more than 300 genotypes of human NPEV identified using new methods of molecular detection. ${ }^{5}$

Many studies focus on identifying the species and genotype of NPEV that is implicated in an outbreak. For example, outbreaks of aseptic meningitis in Europe within the last decade have been associated with echovirus $30 .{ }^{6}$ In comparison, enterovirus-D68 (EV-D68) is thought to be linked to an upsurge of AFP cases across Northern Europe and the United States in 2016. ${ }^{7}$ Enterovirus-A71 (EV-A71) is known to be particularly neurovirulent and associated with fatalities, particularly within the Asia-Pacific region. ${ }^{8}$ Typically, EV-A71 presents with hand, foot, and mouth disease, which is a benign and self-limiting condition. However, EV-A71 can also cause neurological infections such as those discussed in this review, which can then have a severe impact. ${ }^{8}$ For example, outbreaks of EV-A71 in Singapore resulted in closure of schools to prevent ongoing transmission. ${ }^{9}$ Despite the apparent predominance of certain EV genotypes in these diseases, the associations between different EV genotypes have not been statistically compared in meta-analyses for AFP, encephalitis, and meningitis.

In response to the potential for EVs to inflict severe neurological disease, the World Health Organization (WHO) considered NPEVs in the WHO Research and Development Blueprint for the first time in 2018. ${ }^{10}$ NPEVs were deemed to require further research and development after being classified as a major public health threat. This systematic review is timely given this update, and also because of the ongoing development of vaccines. Phase III trials of an inactivated vaccine against EV-A71 in Taiwan have demonstrated seroprotection persisting for 2 years in most participants. ${ }^{11}$

NPEVs have been detected in different sites during episodes of neurological conditions. In order to make a definitive diagnosis of viral encephalitis or meningitis, CNS involvement needs to be confirmed, such as by detection of virus in the cerebrospinal fluid (CSF). ${ }^{12} \mathrm{How}$ ever, diagnosis may also be made when EVs are detected from other sites including stool, serum, and throat swabs. ${ }^{13}$ Knowledge of which sampling site is most commonly assessed and which sites are more commonly positive may assist in the improvement of sampling guidelines.
Traditionally, virus isolation and serology neutralization methods were used for diagnosis of EVs, though these were time-consuming and labour-intensive. ${ }^{14}$ Conventional immunological diagnosis methods have been shown to be less specific than molecular assays based on reverse transcription-polymerase chain reaction (RT-PCR) targeting various genomic regions. ${ }^{15}$ The optimal target for EV detection and identification used to date has been VP1, which is a capsid protein located at the virion surface. ${ }^{16}$ Two other structural proteins, VP4 and VP2, have also been used for EV identification, though with less success than VP1. ${ }^{16,17}$ However, before these structural proteins were identified as targets, highly conserved sequences in the $5^{\prime}$ untranslated region ( $5^{\prime}$ UTR) were amplified for EV RT-PCR and genotypes imputed using sequencing. This method was later suggested to be more suitable for detection of the presence of an NPEV rather than genotyping. ${ }^{17}$ Given the proposed differences in sensitivity and efficacy of these targets, we aimed to obtain an estimate of which genotyping methods and targets are more prevalent across the selected studies.

Previous reviews in this area have either focused on a single neurological complication or have been limited geographically to one country or region. ${ }^{18-21}$ The objective of this review was to conduct a systematic search of the published literature to ascertain which NPEV genotypes were globally most often diagnosed in cases of neurological complications. Secondary objectives included recording the sampling site and method of genotyping for these data.

\section{2 | METHODS}

\section{1 | Literature search}

Preferred Reporting Items for Systematic Reviews and Meta-analyses (PRISMA) guidelines were followed in the reporting of this review. ${ }^{22}$ The completed PRISMA checklist is provided in Table S1.

Two reviewers (S. S. and S. S. B.) conducted a systematic search for observational studies describing cases of NPEV AFP, encephalitis, or meningitis, which identified specific genotypes of EVs. Databases searched were MEDLINE and Embase from each database's date of inception to 29 January 2019. The database search strategy was created with a focus on terms for the virus and the terms for genotype. These were combined with terms for any of the targeted diseasesAFP, encephalitis, or meningitis. A combination of key words and relevant subject headings specific to each database were also included and listed in the full search strategy for MEDLINE in Table S2. No further limits were applied. Finally, the reference lists of the chosen articles were screened manually to obtain more articles after title and abstract exclusions.

\section{2 | Inclusion criteria}

Included studies were observational studies or surveillance reports concerning patients diagnosed with AFP, encephalitis or meningitis where specific genotypes of NPEV were identified from any sample 
site. No requirements were specified for the method of diagnosis used; thus, each condition was recorded as reported by the author(s).

\section{3 | Exclusion criteria}

Exclusion criteria were as follows: (1) studies not presenting original data or those in the form of letters, conference abstracts, and comments; (2) studies that presented data in aggregate formats; (3) studies that reported fewer than 10 NPEV samples or that genotyped less than $50 \%$ of the NPEV-positive samples, and (4) studies limited to high-risk populations such as immunodeficient patients. Where we found multiple publications from one study, we selected only the paper with the longest follow-up time or the largest sample size.

\section{4 | Data abstraction}

\subsection{1 | Study selection}

One author (S. S.) initially removed duplicate studies from the results of the search. Two authors (S. S. and S. S. B.) then independently screened the titles and abstracts of the remaining studies. This was done with blinding of authors and journal titles, using a Microsoft Excel workbook specifically designed for screening. ${ }^{23}$ Items for which there was disagreement were discussed by the two screeners and resolved by consensus. The full texts of the eligible studies were then obtained and divided into English and non-English studies. Attempts were made to find translations of non-English studies, but where this was not possible, the non-English papers were not included in the analysis. These studies are outlined in Table S3 with data extracted from the abstracts. Authors of the English studies unable to be obtained in full were contacted to request the manuscript. The remaining English studies were assessed for eligibility with reasons for exclusion detailed in Figure 1.

\subsection{2 | Data extraction and quality assessment}

We separated the final 96 studies into the three neurological complications of interest: AFP, ${ }^{24-42}$ encephalitis, ${ }^{43-63}$ and meningitis. ${ }^{26,48,56,58,64-119}$ The "encephalitis" category also encompassed cases of rhombencephalitis, meningoencephalitis, and studies that did not distinguish between meningitis and encephalitis. As well as those patients explicitly diagnosed with AFP, patients diagnosed as having "myelitis" were included in the "AFP" category. Four studies included participants in two of the complication categories and were thus extracted separately in each category. ${ }^{26,48,56,58}$

The following five pieces of descriptive data were extracted into three separate Microsoft Excel workbooks for each neurological condition: (a) the citation of the study, (b) the country and the region designated by WHO that the study was conducted in, (c) the duration of the study, (d) whether the study was prospective or retrospective, and (e) whether the data were sourced from surveillance or hospital records.
The primary outcome was documented as the total number of NPEV positive samples, which were genotyped, including nontypable samples and those that were only typed into species or not reported. This was further divided into the number of samples allocated to each genotype. If two methods of genotyping were used generating different results, the one method with the higher number of successful genotypes identified was included. If multiple specimens were positive for the same viral genotype from one patient, they were recorded as one case. Data were extracted from figures using WebPlotDigitizer where needed. ${ }^{120}$ The following five secondary outcomes were collected along with the descriptive data and primary outcomes in the Microsoft Excel workbooks: (a) the site of sampling, (b) the age of participants, (c) the method of genotyping used, (d) the method of diagnosis of the condition, and (e) whether the source of material genotyped was isolated virus or nucleic acid direct from clinical sample.

Where necessary, authors of the selected studies were contacted via email to obtain missing data for the outcomes of interest. Authors of $4 / 17(23.53 \%)$ studies that were contacted provided additional information. ${ }^{31,82,107,114}$

The quality of each selected article was scored according to the Centre for Evidence-Based Medicine (CEBM's) levels of evidence ver. 2011. ${ }^{121}$ Disagreement in study appraisal was resolved by consensus.

\section{5 | Data analysis}

We conducted proportion meta-analyses with STATA 15.1 (StataCorp LP, College Station, TX, USA) using the "metaprop" command for the most common genotypes in each disease. ${ }^{122}$ The pooled proportion was calculated with the total number of NPEV samples on which genotyping was performed as the denominator. The Freeman-Tukey variant of the arcsine transformation was applied to stabilize the variance of proportions. ${ }^{123} \mathrm{~A}$ random effects model was employed, as there was significant heterogeneity anticipated given the nature of observational studies. ${ }^{124}$ Confidence intervals $(95 \% \mathrm{Cl})$ were calculated using the DerSimonian and Laird method. ${ }^{125}$ We calculated the $I^{2}$ statistic as a measure of the proportion of the overall variation that was attributable to between-study heterogeneity. Secondary outcomes were assessed using descriptive statistics generated through Microsoft Excel ver. 16.23 (Microsoft Corporation, Redmond, WA, USA). Due to the small number of studies in each arm of analysis, thorough subgroup analyses were not performed. However, we performed preliminary subgroup analyses of four AFP ${ }^{33,37,39,41}$ and four encephalitis ${ }^{49,51,56,62}$ papers, which genotyped nucleic acid direct from clinical sample, to assess for laboratory method bias.

\section{3 | RESULTS}

\section{1 | Results of literature search}

An adapted PRISMA flow diagram shows the process followed to select the studies used in this review (Figure 1). ${ }^{22}$ The initial search yielded 1245 potential references, and three additional articles were 


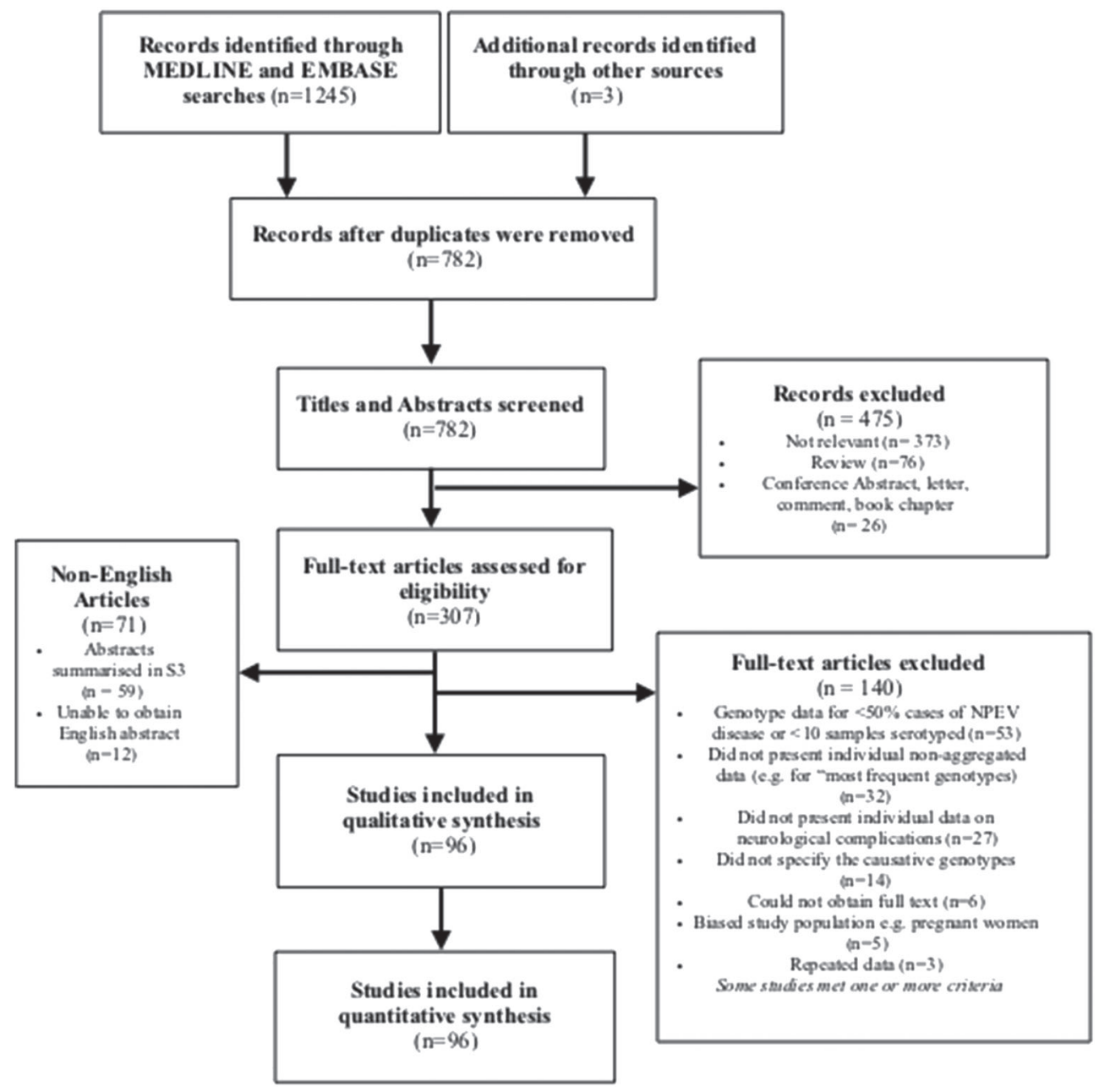

FIGURE 1 Search strategy for the identification of studies reporting which enterovirus (EV) genotypes were prevalent in acute flaccid paralysis, encephalitis, and meningitis.

a "Not relevant" included studies focusing on diagnostics or therapeutics, studies of nonhuman EVs, evaluations of surveillance studies, studies of non-central nervous system manifestations, studies on polioviruses or other viruses, studies on environmental samples of EV exclusively, studies with coinfections of other viruses, papers on whole genome sequencing of particular strains, and single participant case studies obtained through hand searching of the bibliographies of included studies. There were 96 articles published since 1962 included in this systematic review. Four papers including data on two neurological complications were recorded for both complications, generating a total of 19 AFP studies, 21 encephalitis studies, and 60 meningitis studies. In total, there were 37729 patients: $3779 / 37729$ (10.02\%) AFP cases, 1140/37 729 (3.02\%) encephalitis cases, and 32 810/37 729 (86.96\%) meningitis cases. The majority of studies were from the Western Pacific Region (30/96, 31.25\%) or the European Region (29/96, 30.2\%).

A comparison of descriptive data for the three conditions is shown in Table S4. For AFP, 10 studies $^{24,31,34-36,38-42}$ used the WHO criteria as a method of diagnosis, one study ${ }^{33}$ used separate criteria designated by a neurologist, and the remaining eight studies ${ }^{25-30,32,37}$ did not report the criteria for diagnosis. Methods of diagnosis for cases of encephalitis and meningitis were not consistently reported; thus, these data were not collated.

Studies included in this review were eligible to be graded from levels $1 \mathrm{~b}$ to 4 of CEBM's five levels. Of the 96 studies, 67 (69.79\%) studies scored $2 \mathrm{~b}$ or higher. The studies and corresponding CEBM levels are listed in Tables 1-3 according to the three neurological diseases.

\section{2 | NPEV genotypes}

The genotype distributions were analysed within each neurological complication and are presented in Tables 4-6. Each proportion should be considered as a pooled estimate of only those studies reporting the particular genotype. Hence, cumulative point estimates do not sum to $100 \%$. Across AFP studies, EV-A71 was the most common genotype detected, yielding a pooled proportion of $0.12(95 \% \mathrm{Cl}$, 0.05-0.20). Other common genotypes were echovirus $13(0.08,95 \%$ $\mathrm{Cl}, 0.05-0.12)$ and echovirus $11(0.07,95 \% \mathrm{Cl}, 0.05-0.09)$. For cases of encephalitis, EV-A71 was also the most frequent virus detected, $(0.77,95 \% \mathrm{Cl}, 0.61-0.91)$. This was followed by echovirus $30(0.20$, $95 \% \mathrm{Cl}, 0.03-0.44)$ and echovirus $18(0.17,95 \% \mathrm{Cl}, 0.00-0.53)$. In contrast, echovirus 30 was the most prominent genotype detected in meningitis patients $(0.35,95 \% \mathrm{Cl}, 0.27-0.42)$. After echovirus 30 , echovirus $6(0.13,95 \% \mathrm{Cl}, 0.27-0.42)$ and echovirus $13(0.13,95 \% \mathrm{Cl}$, 0.07-0.19) were most prevalent. The results of our preliminary subgroup analyses in AFP and encephalitis papers, which genotyped nucleic acid direct from clinical sample, demonstrated similar trends as above. Across both AFP $(0.47,95 \% \mathrm{Cl}, 0.02-0.95)$ and encephalitis $(0.62,95 \% \mathrm{Cl}, 0.19-0.96)$ studies, EV-A71 was the most predominant virus detected in these analyses. 
TAB LE 1 Characteristics of the studies included in the meta-analysis of AFP cases listed by WHO region

\begin{tabular}{|c|c|c|c|c|}
\hline First Author, Year & Study Period & CEBM Level & Cases, $\mathrm{n}$ & Most Prevalent EV Genotype(s) \\
\hline \multicolumn{5}{|l|}{ African Region } \\
\hline Oyero, $2014^{24}$ & N/A & $3 b$ & 56 & Echovirus 11 \\
\hline \multicolumn{5}{|c|}{ Eastern Mediterranean Region } \\
\hline Bahri, $2005^{26}$ & $1992-2003$ & $3 b$ & 54 & Coxsackie virus B3, echovirus 6 \\
\hline Angez, $2015^{28}$ & 2013 & $2 b$ & 215 & Echovirus 19 \\
\hline Shaukat, $2012^{29}$ & 2009 & $3 b$ & 23 & Echovirus 3, echovirus 11 \\
\hline Saeed, $2007^{30}$ & 2003 & $1 b$ & 474 & Echovirus 6 \\
\hline Angez, $2017^{31}$ & 2003 & $2 b$ & 63 & Coxsackie virus B5 \\
\hline \multicolumn{5}{|l|}{ European Region } \\
\hline \multicolumn{5}{|l|}{ South-East Asian Region } \\
\hline Laxmivandana, $2013^{34}$ & $2009-2010$ & $2 b$ & 422 & Enterovirus-A76 \\
\hline Maan, $2013^{35}$ & 2010 & $2 b$ & 54 & Echovirus 13 \\
\hline Rao, $2012^{36}$ & 2007-2009 & $3 b$ & 666 & Enterovirus-A71 \\
\hline \multicolumn{5}{|l|}{ Western Pacific Region } \\
\hline Zhou, $2016^{37}$ & 2010-2013 & $2 b$ & 26 & Enterovirus-A71 \\
\hline Apostol, $2012^{38}$ & $1992-2008$ & $2 b$ & 386 & Coxsackie virus A24 \\
\hline Tang, $2014^{39}$ & 2006-2010 & $3 b$ & 98 & Echovirus 13 \\
\hline
\end{tabular}

Abbreviations: AFP: acute flaccid paralysis; CEBM: Centre for Evidence-Based Medicine; EV: enterovirus; WHO: World Health Organisation.

\section{3 | Secondary outcomes}

All 96 studies reported method of typing and sampling site. These data are presented in Table 7 and Figure 2. The most commonly used method of genotyping was RT-PCR (80/96, 83.33\%). The structural protein VP1 was the most utilized RT-PCR target (44/96 studies, 45.83\%). Only one included study published in 1998 used virus isolation as a means of typing. ${ }^{92}$ The majority of the samples were CSF alone or in addition to other samples (72/96 studies, $75.00 \%$ ). Stool was the next most prevalent sample type after CSF with 18/96 studies (18.75\%) relying on stool samples alone.

\section{4 | DISCUSSION}

In this review, the most common NPEV associated with AFP and encephalitis was EV-A71, and echovirus 30 was the most common NPEV associated with meningitis.

\section{1 | AFP genotypes}

The most commonly identified genotypes in AFP cases after EV-A71 were echovirus 13 and echovirus 11 . This is consistent with results from another systematic review of AFP surveillance cases, which found that the most commonly associated genotypes were EV-A71 (7.9\%) and echovirus 11 (5.7\%). ${ }^{18}$ In contrast, Suresh et al found that in case reports and case series, EV-D68 was the next most prevalent genotype after EV-A71. However, EV-D68 was not amongst the 10 most prevalent genotypes identified in the data presented here. This may be explained by our exclusion of case reports and case series involving less than 10 patients. Moreover, EV-D68 is most commonly detected in respiratory specimens, and as demonstrated in our review, most EV surveillance and outbreak programs used CSF or stool as analyte. ${ }^{13}$ There have also been difficulties with EV-D68 detection due to cross-reactivity with rhinoviruses in various diagnostic settings. ${ }^{126}$ Thus, both sampling and laboratory biases may have impacted the comparatively low proportion of EV-D68 in our dataset.

This affects the issues surrounding EV-D68 detection and causality in neurological syndromes. The Centers for Disease Control and Prevention $(C D C)$ has reported a temporal association with EVD68 respiratory illness and acute flaccid myelitis (AFM) cases in the United States, prompting ongoing surveillance. ${ }^{127}$ However, the limited detection of EV-D68 in neurological specimens has led to 
TABLE 2 Characteristics of the studies included in the meta-analysis of Encephalitis cases listed by WHO region

\begin{tabular}{|c|c|c|c|c|}
\hline First Author, Year & Study Period & CEBM Level & Cases, $\mathbf{n}$ & Most Prevalent EV Genotype(s) \\
\hline \multicolumn{5}{|l|}{ African Region } \\
\hline Schoub, $1985^{43}$ & 1984 & $2 b$ & 10 & Coxsackie virus B3 \\
\hline Dalwai, $2009^{44}$ & $2003-2006$ & $2 b$ & 29 & Echovirus 9 \\
\hline \multicolumn{5}{|l|}{ European Region } \\
\hline Taravilla, $2019^{46}$ & 2016 & $2 b$ & 18 & Enterovirus-A71 \\
\hline Papa, $2009^{47}$ & $2006-2007$ & $3 b$ & 27 & Echovirus 6 \\
\hline \multicolumn{5}{|l|}{ Region of the Americas } \\
\hline Tavakoli, $2008^{48}$ & $2005-2006$ & $2 b$ & 11 & Coxsackie virus B3 \\
\hline \multicolumn{5}{|c|}{ South-East Asian Region } \\
\hline Kumar, $2013^{52}$ & $2009-2010$ & 4 & 31 & Coxsackie virus B5, echovirus 3, Echovirus 6 \\
\hline \multicolumn{5}{|l|}{ Western Pacific Region } \\
\hline Zhang, $2013^{53}$ & $2002-2012$ & 4 & 233 & Echovirus 30 \\
\hline Wei, $2016^{54}$ & 2015 & $2 b$ & 26 & Echovirus 30 \\
\hline $\mathrm{He}, 2013^{55}$ & 2010 & $1 b$ & 33 & Enterovirus-A71 \\
\hline Huang, $2015^{56}$ & $2009-2013$ & $2 b$ & 211 & Enterovirus-A71 \\
\hline Ho, $1999^{57}$ & 1998 & $2 b$ & 39 & Enterovirus-A71 \\
\hline Chen, $2018^{58}$ & 2013-2015 & $2 b$ & 97 & Echovirus 18 \\
\hline
\end{tabular}

Abbreviations: CEBM: Centre for Evidence-Based Medicine; EV: enterovirus; WHO: World Health Organisation.

debate regarding the role of the genotype in causing disease. ${ }^{128}$ Application of the Bradford-Hill criteria has supported a causal relationship between EV-D68 and AFM. ${ }^{128}$ Moreover, in 2017, an experimental mouse model was inoculated with EV-D68, inducing a paralytic disease resembling AFM. ${ }^{129}$ This model demonstrated all of Koch's postulates, supporting the hypothesis that EV-D68 can cause AFM. However, Koch's postulates have been revisited over time in light of developments in virus diagnostics. In postulates developed by Huebner, he considers the importance of tissue culture isolation; whereas Fredricks and Relman require sequencebased evidence for microbial causation. ${ }^{130,131}$ This mouse model has yet to satisfy these modified postulates of microbial pathogenesis and thus requires further development to prove causality of EVD68 and AFM. This review suggests the need for more detailed analysis of AFP cases where EV-D68 is detected. In addition, analysis of respiratory specimens in cases of AFP, as introduced by the CDC's surveillance, may allow for more sensitive detection of this genotype. $^{132}$

\subsection{Encephalitis genotypes}

The most common EV genotypes identified in cases of encephalitis were EV-A71, echovirus 30, and echovirus 18. This is consistent with findings from the California Encephalitis Project in 1998 to 2005, which is one of few large-scale surveillance studies compiling encephalitis incidence data. ${ }^{133}$ In California, EVA-71 in particular was associated with severe illness, with two of the four fatalities in the surveillance being attributed to EVA-71. This aligns with results from our study demonstrating that EVA-71 was proportionally higher in encephalitis rather than the typically less severe meningitis. At present, there are limitations to studying the genetic determinants of the genotype's neurovirulence. For example, there are restrictions concerning existing animal models, as humans are the only natural host for wild-type EV-A71 infection. ${ }^{134}$ A recent study successfully infected NOD-scid IL2R ${ }^{-/-}$(NSG) mice with human immune systems, allowing insights into the human immune response to EV-A71 infection. ${ }^{135}$ This may provide a platform to evaluate EV-A71 therapies in the future. 
TABLE 3 Characteristics of the studies included in the meta-analysis of Meningitis cases listed by WHO region

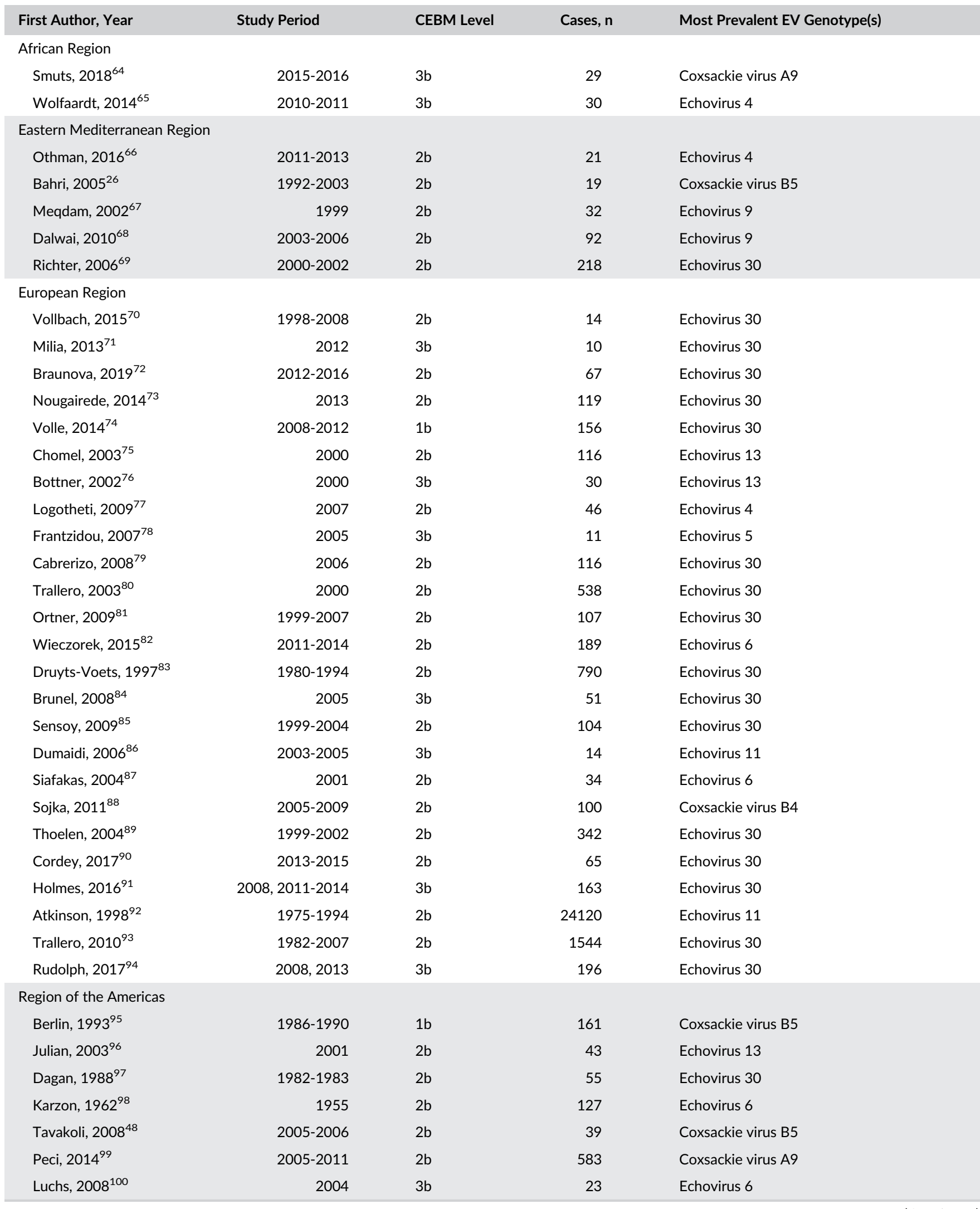


TABLE 3 (Continued)

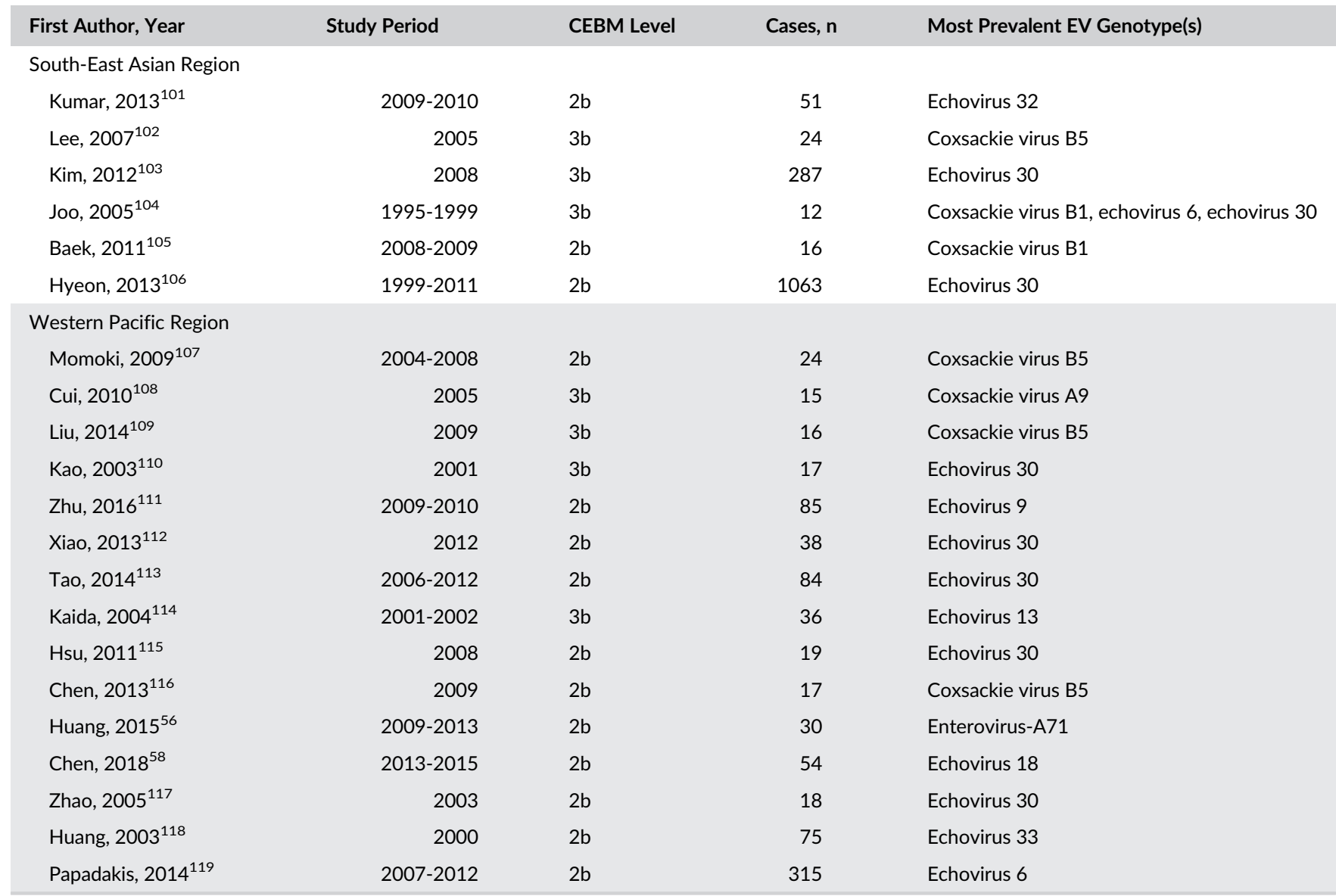

Abbreviations: CEBM: Centre for Evidence-Based Medicine; EV: enterovirus; WHO: World Health Organisation.

TAB LE 4 Proportion of NPEV genotypes reported in the analyzed AFP cases

\begin{tabular}{|llll|}
\hline Genotype & Studies, $\mathbf{n}$ & Proportion (95\% Cl) & $I^{2}$ \\
\hline Enterovirus-A71 & 11 & $0.12(0.05-0.20)$ & 96.62 \\
\hline Echovirus 13 & 12 & $0.08(0.05-0.12)$ & 90.17 \\
\hline Echovirus 11 & 12 & $0.07(0.05-0.09)$ & 78.9 \\
\hline Echovirus 6 & 12 & $0.06(0.04-0.09)$ & 87.94 \\
\hline Coxsackie virus B3 & 11 & $0.05(0.03-0.09)$ & 85.32 \\
\hline Coxsackie virus A24 & 7 & $0.05(0.01-0.09)$ & 92.96 \\
\hline Echovirus 7 & 12 & $0.04(0.03-0.05)$ & 59.77 \\
\hline Coxsackie virus B5 & 10 & $0.04(0.02-0.06)$ & 72.06 \\
\hline Echovirus 14 & 10 & $0.04(0.02-0.06)$ & 77.19 \\
\hline Echovirus 19 & 9 & $0.04(0.02-0.06)$ & 81.42 \\
\hline Other & 18 & $0.6(0.52-0.67)$ & 94.16 \\
\hline
\end{tabular}

Abbreviations: AFP: acute flaccid paralysis; NPEV: nonpolio enterovirus.

\section{3 | Meningitis genotypes}

The most common EV genotypes identified in cases of meningitis were echovirus 30 , echovirus 6 , and echovirus 13 . Echovirus 30 has been responsible for numerous outbreaks in continents including Asia ${ }^{103,112,117}$ and Europe, ${ }^{71,73,81}$ indicating an active global circulation of this genotype. The predominance of echovirus 30 in cases of viral
TAB LE 5 Proportion of NPEV genotypes reported in the analyzed encephalitis cases

\begin{tabular}{|lcll|}
\hline Genotype & Studies, $\mathrm{n}$ & Proportion $(95 \% \mathrm{Cl})$ & $\mathbf{I}^{\mathbf{2}}$ \\
\hline Enterovirus-A71 & 10 & $0.77(0.61-0.91)$ & 93.45 \\
\hline Echovirus 30 & 5 & $0.20(0.03-0.44)$ & 95.72 \\
\hline Echovirus 18 & 3 & $0.17(0.00-0.53)$ & 93.8 \\
\hline Echovirus 6 & 6 & $0.13(0.06-0.22)$ & 77.82 \\
\hline Coxsackie virus B5 & 10 & $0.11(0.05-0.18)$ & 71.78 \\
\hline Other & 20 & $0.53(0.34-0.71)$ & 97.26 \\
\hline
\end{tabular}

Abbreviation: NPEV: nonpolio enterovirus.

meningitis has not been entirely explained, with research continually being done into its mechanism of disease. In particular, Bernit et al suggested that echovirus 30 transmission may not be strictly faecaloral as other NPEVs are, but this theory is yet to be substantiated. ${ }^{136}$ Consequently, as with EV-A71, the reasons for the neurovirulence of echovirus 30 have yet to be comprehensively ascertained. Our review thus confirms the importance of research into specific virulence factors and treatments in each of these prevalent genotypes.

\section{4 | Genotyping method}

The most common method of genotyping used was RT-PCR. The structural protein VP1 was the target for RT-PCR amplification in 
TAB LE 6 Proportion of NPEV genotypes reported in the analyzed meningitis cases

\begin{tabular}{|lcll|}
\hline Genotype & Studies, $\mathbf{n}$ & Proportion, 95\% Cl & \multicolumn{1}{l|}{$I^{2}$} \\
\hline Echovirus 30 & 41 & $0.35(0.27-0.42)$ & 98.74 \\
\hline Echovirus 6 & 36 & $0.16(0.11-0.21)$ & 96.37 \\
\hline Echovirus 13 & 23 & $0.13(0.07-0.19)$ & 96.95 \\
\hline Coxsackie virus A7 & 2 & $0.10(0.10-0.10)$ & 0.00 \\
\hline Echovirus 9 & 27 & $0.07(0.05-0.09)$ & 89.41 \\
\hline Coxsackie virus A9 & 22 & $0.07(0.04-0.10)$ & 90.14 \\
\hline Echovirus 11 & 20 & $0.07(0.03-0.11)$ & 98.25 \\
\hline Echovirus 18 & 16 & $0.06(0.03-0.10)$ & 92.55 \\
\hline Echovirus 7 & 12 & $0.03(0.01-0.06)$ & 98.04 \\
\hline Echovirus 19 & 3 & $0.03(0.00-0.14)$ & 98.92 \\
\hline Other & 54 & $0.47(0.42-0.53)$ & 97.65 \\
\hline
\end{tabular}

Abbreviation: NPEV: nonpolio enterovirus.

TABLE 7 Methods of EV genotyping across all 96 studies

\begin{tabular}{|lc|}
\hline Method of genotyping & Number of studies \\
\hline VP1 RT-PCR & $44 / 96 ; 45.83 \%$ \\
\hline MN assay and VP1 RT-PCR & $12 / 96 ; 12.50 \%$ \\
\hline MN assay & $10 / 96 ; 10.42 \%$ \\
\hline $5^{\prime}$ UTR RT-PCR and VP1 RT-PCR & $8 / 96 ; 8.33 \%$ \\
\hline $5^{\prime}$ UTR RT-PCR & $5 / 96 ; 5.21 \%$ \\
\hline IFA & $6 / 96 ; 6.25 \%$ \\
\hline VP1 RT-PCR and VP4 RT-PCR & $3 / 96 ; 3.13 \%$ \\
\hline MN assay, VP1 RT-PCR and 5'UTR RT-PCR & $2 / 96 ; 2.08 \%$ \\
\hline RT-PCR unspecified target & $2 / 96 ; 2.08 \%$ \\
\hline IFA,VP1 RT-PCR and 5'UTR RT-PCR & $1 / 96 ; 1.04 \%$ \\
\hline VP2 RT-PCR & $1 / 96 ; 1.04 \%$ \\
\hline VP4/2 RT-PCR & $1 / 96 ; 1.04 \%$ \\
\hline Virus isolation & $1 / 96 ; 1.04 \%$ \\
\hline
\end{tabular}

Abbreviations: EV: enterovirus; IFA: immunofluorescence assay; MN: microneutralization; RT-PCR: reverse transcription-polymerase chain reaction.
44/96 studies (45.83\%). This is in line with recent recommendations from the European NPEV Network that RT-PCR with VP1 should be used for diagnosis of EV. ${ }^{17}$ After VP1, VP2, and VP4 are recommended as second-line targets of RT-PCR. The less frequent use of $5^{\prime}$ UTR in our results may be explained by the more conservative nature of the $5^{\prime}$ UTR in comparison to the VP1 gene among EV species. ${ }^{137}$ There has also been more genetic recombination found in the $5^{\prime}$ UTR region in comparison to the VP1 region. ${ }^{138}$ Both these issues have been proposed to explain why a study conducted by Chiang et al demonstrated more false positives and mismatched genotyping associated with 5'UTR than VP1 sequencing., ${ }^{137,138}$ Moreover, the papers included in our review did not utilize Next Generation Sequencing methods. Currently, genome sequencing is a requirement for identification of new recombination events and recombinant EVs, although it is yet to be employed diagnostically on a large scale. ${ }^{17}$ In the future, it is expected that sequencing methods will be readily used for diagnostic EV typing in surveillance and outbreaks, especially as improvements are made in cost and efficiency. ${ }^{17}$

\section{5 | Limitations}

The main benefit of performing this meta-analysis was the improved power and precision gained by pooling estimates of genotype prevalence from individual studies. Our review included studies from all six WHO regions, and $67.97 \%$ of included studies were rated $2 \mathrm{~b}$ or higher according to the CEBM criteria.

Nonetheless, this review poses a number of limitations. Firstly, there is a risk of publication bias, due to the exclusion of both grey literature and conference abstracts that did not provide sufficient data for analysis. We attempted to minimize this risk through a comprehensive literature search strategy and secondary hand-searching of bibliographies from included studies. Secondly, the exclusion of nonEnglish studies from the meta-analyses may lead to language-bias. To minimize this, we reviewed the non-English abstracts presented in Table S3. Furthermore, the reliance on reported clinical diagnoses of the neurological conditions may be associated with inaccuracies, as there is often clinical overlap between encephalitis and meningitis.

FIGURE 2 Site of sampling of specimens across all 96 studies

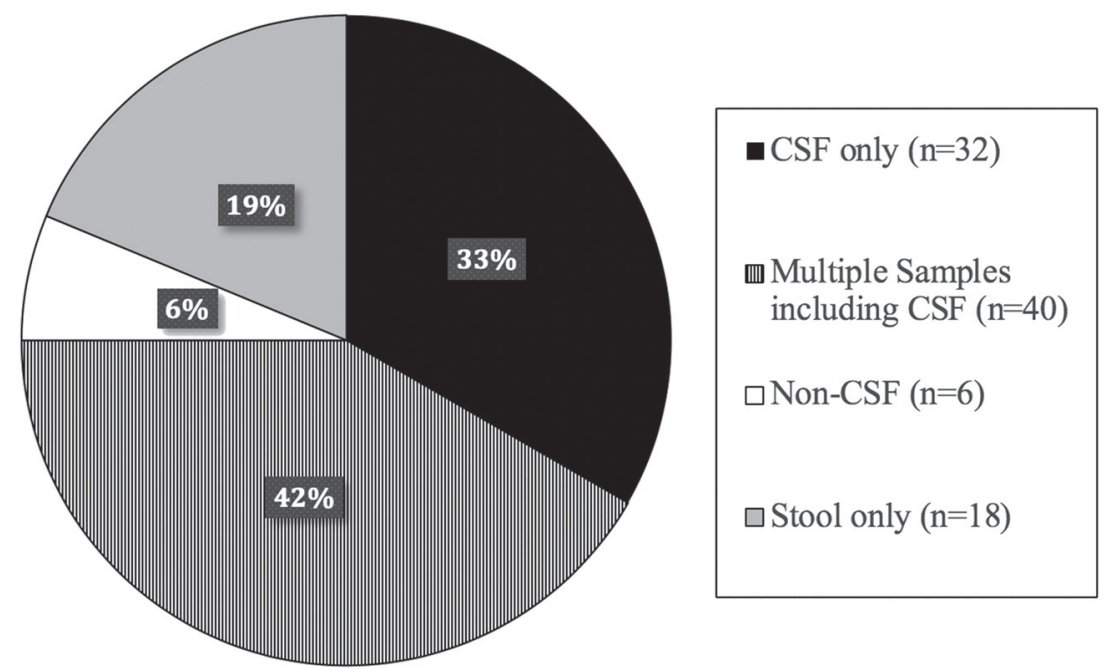


Finally, it is possible that other neurotropic EVs, which are less easily isolated or detected, may contribute to a greater degree than is apparent in our review. This could also be influenced by the source of material genotyped: isolated viruses or nucleic acid direct from clinical sample. We were not able to perform extensive subgroup analyses in this regard due to a restricted sample size, particularly in the isolated viruses arm of analysis. However, brief subgroup analyses of four AFP and four encephalitis papers, which genotyped nucleic acid direct from clinical sample, revealed similar trends to the global analysis. It is expected that more thorough diagnostic guidelines for EV neurological complications and advancement in Next Generation Sequencing will improve these limitations for future research in this subject area.

\section{5 | CONCLUSIONS}

This first meta-analysis of the global genotype distribution of EVs for AFP, encephalitis, and meningitis shows that the predominant EV genotypes differed between these conditions. Review demonstrated that the most common genotypes were EV-A71 for AFP and encephalitis, and echovirus 30 for meningitis. This epidemiological knowledge may assist in directing development in diagnostics and therapeutics for EV neurological infections. Given the potentially severe outcomes of such infections, attempts to characterize the neurovirulence of the different genotypes must continue. This research will be aided by development of Next Generation Sequencing techniques, more rigorous surveillance programs, and advances in EV treatments and vaccines.

\section{ACKNOWLEDGEMENTS}

The authors would like to acknowledge the contributions of statistician Dr Zhixin Liu, UNSW Stats Central, for her assistance with designing and finalizing the data analysis.

\section{CONFLICTS OF INTEREST}

The authors have no conflicts of interest to disclose.

\section{ORCID}

Sarika Suresh (iD https://orcid.org/0000-0003-1525-6749

William D. Rawlinson (D) https://orcid.org/0000-0003-0988-7827

Sacha Stelzer-Braid (iD https://orcid.org/0000-0001-6037-9305

\section{REFERENCES}

1. Rudolph $\mathrm{H}$, Schroten $\mathrm{H}$, Tenenbaum $\mathrm{T}$. Enterovirus infections of the central nervous system in children: an update. Pediatr Infect Dis J. 2016;35(5):567-569.

2. Kroneman A, Vennema $H$, Deforche $K$, et al. An automated genotyping tool for enteroviruses and noroviruses. J Clin Virol. 2011 51(2):121-125.
3. Kew OM, Sutter RW, de Gourville EM, Dowdle WR, Pallansch MA. Vaccine-derived polioviruses and the endgame strategy for global polio eradication. Annu Rev Microbiol. 2005;59(1):587-635.

4. Dalldorf G, Sickles GM, Plager H, Gifford R. A virus recovered from the feces of poliomyelitis patients pathogenic for suckling mice. $J$ Exp Med. 1949;89(6):567-582.

5. The Online (10th) Report of the International Committee on Taxonomy of Viruses. Genus: Enterovirus.5. https://talk.ictvonline.org/ictv-reports/ictv_online_report/positive-sense-rna-viruses/picornavirales/w/picornaviridae/681/genus-enterovirus. Accessed May 28, 2019.

6. Nougairede $A$, Bessaud $M$, Thiberville $S$, et al. Widespread circulation of a new echovirus 30 variant causing aseptic meningitis and non-specific viral illness, South-East France, 2013. J Clin Virol. 2014; 61(1):118-124.

7. Aliabadi N, Messacar K, Pastula DM, et al. Enterovirus D68 infection in children with acute flaccid myelitis, Colorado, USA, 2014. Emerg Infect Dis. 2016;22(8):1387-1394.

8. Cardosa M, Perera D, Brown B, et al. Molecular epidemiology of human enterovirus 71 strains and recent outbreaks in the AsiaPacific Region: comparative analysis of the VP1 and VP4 genes. Emerg Infect Dis. 2003;9(4):461-468.

9. Siegel K, Cook A, La H. The impact of hand, foot and mouth disease control policies in Singapore: a qualitative analysis of public perceptions. J Public Health Policy. 2017;38(2):271-287.

10. Mehand MS, Al Shorbaji F, Millett P, Murgue B. The WHO R\&D Blueprint: 2018 review of emerging infectious diseases requiring urgent research and development efforts. Antiviral Res. 2018;159: 63-67.

11. Huang LM, Chiu CH, Chiu NC, et al. Immunogenicity, safety, crossreaction, and immune persistence of an inactivated enterovirus $\mathrm{A} 71$ vaccine in children aged from two months to 11 years in Taiwan. Vaccine. 2019;37(13):1827-1835.

12. The United Kingdom Acute Flaccid Paralysis AFP Task Force. An increase in reports of acute flaccid paralysis (AFP) in the United Kingdom, 1 January 2018-21 January 2019: early findings. Euro Surveill. 2019;24:1900093.

13. Maan HS, Dhole TN, Chowdhary R. Identification and characterization of nonpolio enterovirus associated with nonpolio-acute flaccid paralysis in polio endemic state of Uttar Pradesh, Northern India. PLoS ONE. 2019;14(1):e0208902.

14. Rotbart HA, Kinsella JP, Wasserman RL. Persistent enterovirus infection in culture-negative meningoencephalitis: demonstration by enzymatic RNA amplification. J Infect Dis. 1990;161(4):787-791.

15. Craig ME, Robertson P, Howard NJ, Silink M, Rawlinson WD. Diagnosis of enterovirus infection by genus-specific PCR and enzymelinked immunosorbent assays. J Clin Microbiol. 2003;41(2):841-844.

16. Harvala $\mathrm{H}$, Broberg $\mathrm{E}$, Benschop $\mathrm{K}$, et al. Recommendations for enterovirus diagnostics and characterisation within and beyond Europe. J Clin Virol. 2018;101:11-17.

17. Casas I, Palacios GF, Trallero G, Cisterna D, Freire MC, Tenorio A. Molecular characterization of human enteroviruses in clinical samples: comparison between VP2, VP1, and RNA polymerase regions using RT nested PCR assays and direct sequencing of products. $J$ Med Virol. 2001;65(1):138-148.

18. Suresh S, Forgie S, Robinson J. Non-polio Enterovirus detection with acute flaccid paralysis: a systematic review. J Med Virol. 2018; 90(1):3-7.

19. Tapparel C, Siegrist F, Petty TJ, Kaiser L. Picornavirus and enterovirus diversity with associated human diseases. Infect Genet Evol. 2013;14:282-293.

20. Koh WM, Bogich T, Siegel K, et al. The epidemiology of hand, foot and mouth disease in asia: a systematic review and analysis. Pediatr Infect Dis J. 2016;35(10):e285-e300. 
21. Joshi R, Kalantri SP, Reingold A, Colford JM Jr. Changing landscape of acute encephalitis syndrome in India: a systematic review. Natl Med J India. 2012;25:212-220.

22. Moher D, Liberati A, Tetzlaff J, Altman DG. Preferred reporting items for systematic reviews and meta-analyses: the PRISMA statement. BMJ. 2009;339(jul21 1):b2535.

23. Vonville H. Excel Workbook for Screening Titles and Abstracts. In. Houston, TX, USA: University of Texas School of Public Health Library; 2015.

24. Oyero OG, Adu FD, Ayukekbong JA. Molecular characterization of diverse species enterovirus-B types from children with acute flaccid paralysis and asymptomatic children in Nigeria. Virus Res. 2014;189: 189-193.

25. Sadeuh-Mba SA, Bessaud M, Massenet D, et al. High frequency and diversity of species $C$ enteroviruses in Cameroon and neighboring countries. J Clin Microbiol. 2013;51(3):759-770.

26. Bahri O, Rezig D, Nejma-Oueslati BB, et al. Enteroviruses in Tunisia: virological surveillance over 12 years (1992-2003). J Med Microbiol. 2005;54(1):63-69.

27. Shaukat S, Angez M, Alam MM, et al. Characterization of a novel enterovirus genotype and an enterovirus EV-B93 isolated from acute flaccid paralysis patients. PLoS ONE. 2013;8(11):e80040.

28. Angez M, Shaukat S, Zahra R, et al. Identification of new genotype of Echovirus 19 from children with Acute Flaccid Paralysis in Pakistan. Sci Rep. 2015;5(1):17456.

29. Shaukat S, Angez M, Alam MM, et al. Characterization of non-polio enterovirus isolates from acute flaccid paralysis children in Pakistan reflects a new genotype of EV-107. Virus Res. 2012;170(1-2): 164-168.

30. Saeed M, Zaidi SZ, Naeem A, et al. Epidemiology and clinical findings associated with enteroviral acute flaccid paralysis in Pakistan. BMC Infect Dis. 2007;7(1):6.

31. Angez M, Shaukat $S$, Zahra R, et al. Characterization of group B coxsackieviruses isolated from non-polio acute flaccid paralysis patients in Pakistan: vital assessment before polio eradication. Epidemiol Infect. 2017;145(12):2473-2481.

32. Wieczorek M, Krzysztoszek A. Molecular characterization of enteroviruses isolated from acute flaccid paralysis cases in Poland, 1999-2014. Pol J Microbiol. 2017;65:443-450.

33. Sejvar JJ, Lopez AS, Cortese MM, et al. Acute flaccid myelitis in the United States, August-December 2014: results of nationwide surveillance. Clin Infect Dis. 2016;63(6):737-745.

34. Laxmivandana R, Yergolkar P, Gopalkrishna V, Chitambar SD. Characterization of the non-polio enterovirus infections associated with acute flaccid paralysis in South-Western India. PLoS ONE. 2013;8: e61650.

35. Maan HS, Chowdhary R, Shakya AK, Dhole TN. Genetic variants of echovirus 13, northern India, 2010. Emerg Infect Dis. 2013;19(2): 293-296.

36. Rao CD, Yergolkar P, Shankarappa KS. Antigenic diversity of enteroviruses associated with nonpolio acute flaccid paralysis, India, 2007-2009. Emerg Infect Dis. 2012;18:1833-1840.

37. Zhou HT, Guo YH, Chen MJ, et al. Changes in enterovirus serotype constituent ratios altered the clinical features of infected children in Guangdong Province, China, from 2010 to 2013. BMC Infect Dis. 2016;16(1):399.

38. Apostol LN, Suzuki A, Bautista A, et al. Detection of non-polio enteroviruses from 17 years of virological surveillance of acute flaccid paralysis in the Philippines. J Med Virol. 2012;84(4):624-631.

39. Tang J, Yoshida H, Ding Z, et al. Molecular epidemiology and recombination of human enteroviruses from AFP surveillance in Yunnan, China from 2006 to 2010. Sci Rep. 2014;4:6058.

40. Bingjun T, Yoshida H, Yan W, et al. Molecular typing and epidemiology of non-polio enteroviruses isolated from Yunnan Province, the People's Republic of China. J Med Virol. 2008;80(4):670-679.
41. Tao Z, Wang H, Liu Y, et al. Non-polio enteroviruses from acute flaccid paralysis surveillance in Shandong Province, China, 1988-2013. Sci Rep. 2014;4:6167.

42. Kim H, Kang B, Hwang S, et al. Clinical and enterovirus findings associated with acute flaccid paralysis in the Republic of Korea during the recent decade. J Med Virol. 2014;86(9):1584-1589.

43. Schoub BD, Johnson S, McAnerney JM, Dos Santos IL, Klaassen KI. Epidemic Coxsackie B virus infection in Johannesburg, South Africa. J Hyg (Lond). 1985;95:447-455.

44. Dalwai A, Ahmad S, Pacsa A, Al-Nakib W. Echovirus type 9 is an important cause of viral encephalitis among infants and young children in Kuwait. J Clin Virol. 2009;44:48-51.

45. Casas-Alba D, de Sevilla MF, Valero-Rello A, et al. Outbreak of brainstem encephalitis associated with enterovirus-A71 in Catalonia, Spain (2016): a clinical observational study in a children's reference centre in Catalonia. Clin Microbiol Infect. 2017;23(11):874-881.

46. Taravilla CN, Perez-Sebastian I, Salido AG, et al. Enterovirus A71 Infection and Neurologic Disease, Madrid, Spain, 2016. Emerg Infect Dis. 2019;25:25-32.

47. Papa A, Skoura L, Dumaidi K, Spiliopoulou A, Antoniadis A, Frantzidou F. Molecular epidemiology of Echovirus 6 in Greece. Eur J Clin Microbiol Infect Dis. 2009;28(6):683-687.

48. Tavakoli NP, Wang H, Nattanmai S, Dupuis M, Fusco H, Hull R. Detection and typing of enteroviruses from CSF specimens from patients diagnosed with meningitis/encephalitis. J Clin Virol. 2008; 43(2):207-211.

49. Singh DV, Kumar A, Kumar P, et al. An outbreak of encephalitis associated with echovirus 19 in Uttar Pradesh, India, in 2011. Arch Virol. 2016;161(4):967-970.

50. Kumar A, Shukla D, Kumar R, Idris MZ, Misra UK, Dhole TN. An epidemic of encephalitis associated with human enterovirus B in Uttar Pradesh, India, 2008. J Clin Virol. 2011;51:142-145.

51. Kumar A, Shukla D, Kumar R, Idris MZ, Misra UK, Dhole TN. Molecular epidemiological study of enteroviruses associated with encephalitis in children from India. J Clin Microbiol. 2012;50:3509-3512.

52. Kumar A, Shukla D, Srivastava S, Idris MZ, Dhole TN. High frequency of enterovirus genotype circulation in a densely populated area of India. J Infect Dev Ctries. 2013;7:475-483.

53. Zhang L, Yan J, Ojcius DM, et al. Novel and predominant pathogen responsible for the enterovirus-associated encephalitis in eastern China. PLoS ONE. 2013;8(12):e85023.

54. Wei L, Qiong Z, Xiao-Ting S, et al. Molecular epidemiological study of enteroviruses associated with encephalitis in children from Hangzhou, China. Medicine (Baltimore). 2016;95:e4870.

55. He SJ, Han JF, Ding XX, Wang YD, Qin CF. Characterization of enterovirus 71 and coxsackievirus A16 isolated in hand, foot, and mouth disease patients in Guangdong, 2010. Int J Infect Dis. 2013; 17:e1025-e1030.

56. Huang $\mathrm{Y}$, Zhou $\mathrm{Y}$, Lu H, et al. Characterization of severe hand, foot, and mouth disease in Shenzhen, China, 2009-2013. J Med Virol. 2015;87(9):1471-1479.

57. Ho M, Chen ER, Hsu KH, et al. An epidemic of enterovirus 71 infection in Taiwan. Taiwan Enterovirus Epidemic Working Group. N Engl J Med. 1999;341(13):929-935.

58. Chen SP, Huang YC, Li WC, et al. Comparison of clinical features between coxsackievirus $\mathrm{A} 2$ and enterovirus 71 during the enterovirus outbreak in Taiwan, 2008: a children's hospital experience. J Microbiol Immunol Infect. 2010;43(2):99-104.

59. Chen X, Guo J, Li J, et al. Genotypes of human enteroviruses causing pediatric viral encephalitis and meningitis in Hebei province, China, from 2013 to 2015. Pediatr Invest. 2018;2(2):98-104.

60. B'Krong N, Minh NNQ, Qui PT, et al. Enterovirus genotypes in patients with central nervous system and respiratory infections in Viet Nam 1997-2010. Virol J. 2018;15(1):69. 
61. Ryu WS, Kang B, Hong J, Hwang S, Kim J, Cheon DS. Clinical and etiological characteristics of enterovirus 71-related diseases during a recent 2-year period in Korea. J Clin Microbiol. 2010;48:2490-2494.

62. Wang $\mathrm{Y}$, Zou G, Xia A, et al. Enterovirus 71 infection in children with hand, foot, and mouth disease in Shanghai, China: epidemiology, clinical feature and diagnosis. Virol J. 2015;12(1):83

63. Yang KD, Yang MY, Li CC, et al. Altered cellular but not humoral reactions in children with complicated enterovirus 71 infections in Taiwan. J Infect Dis. 2001;183(6):850-856.

64. Smuts H, Cronje S, Thomas J, Brink D, Korsman S, Hardie D. Molecular characterization of an outbreak of enterovirus-associated meningitis in Mossel Bay, South Africa, December 2015-January 2016. BMC Infect Dis. 2018;18:709.

65. Wolfaardt M, Buchner A, Myburgh M, Avenant T, du Plessis NM, Taylor MB. Molecular characterisation of enteroviruses and clinical findings from a cluster of paediatric viral meningitis cases in Tshwane, South Africa 2010-2011. J Clin Virol. 2014;61:400-405.

66. Othman I, Volle R, Elargoubi A, et al. Enterovirus meningitis in Tunisia (Monastir, Mahdia, 2011-2013): identification of virus variants cocirculating in France. Diagn Microbiol Infect Dis. 2016;84(2): 116-122.

67. Meqdam MM, Khalousi MM, Al-Shurman A. Enteroviral meningitis in Northern Jordan: prevalence and association with clinical findings. J Med Virol. 2002;66:224-228.

68. Dalwai A, Ahmad S, Al-Nakib W. Echoviruses are a major cause of aseptic meningitis in infants and young children in Kuwait. Virol J. 2010;7:236

69. Richter J, Koptides D, Tryfonos C, Christodoulou C. Molecular typing of enteroviruses associated with viral meningitis in Cyprus, 2000-2002. J Med Microbiol. 2006;55:1035-1041.

70. Vollbach S, Muller A, Drexler JF, et al. Prevalence, type and concentration of human enterovirus and parechovirus in cerebrospinal fluid samples of pediatric patients over a 10-year period: a retrospective study. Virol J. 2015;12(1):199.

71. Milia MG, Cerutti F, Gregori G, et al. Recent outbreak of aseptic meningitis in Italy due to Echovirus 30 and phylogenetic relationship with other European circulating strains. J Clin Virol. 2013;58: 579-583.

72. Braunova A, Krbkova L, Rainetova P, et al. Clinical and laboratory characteristics of enteroviral meningitis in children, including qRTPCR and sequencing analysis. Biomed Pap Med Fac Univ Palacky Olomouc Czech Repub. 2019.

73. Nougairede A, Bessaud M, Thiberville SD, et al. Widespread circulation of a new echovirus 30 variant causing aseptic meningitis and non-specific viral illness, South-East France, 2013. J Clin Virol. 2014; 61(1):118-124.

74. Volle R, Bailly JL, Mirand A, et al. Variations in Cerebrospinal Fluid Viral Loads Among Enterovirus Genotypes in Patients. Hospitalized With Laboratory-Confirmed Meningitis Due to Enterovirus. J Infect Dis. 2014;210(4):576-584.

75. Chomel JJ, Antona D, Thouvenot D, Lina B. Three ECHOvirus genotypes responsible for outbreak of aseptic meningitis in Rhone-Alpes region, France. Eur J Clin Microbiol Infect Dis. 2003;22(3):191-193.

76. Bottner A, Daneschnejad S, Handrick W, Schuster V, Liebert UG, Kiess W. A season of aseptic meningitis in Germany: epidemiologic, clinical and diagnostic aspects. Pediatr Infect Dis J. 2002;21:11261132.

77. Logotheti M, Pogka V, Horefti E, et al. Laboratory investigation and phylogenetic analysis of enteroviruses involved in an aseptic meningitis outbreak in Greece during the summer of 2007. J Clin Virol. 2009;46(3):270-274

78. Frantzidou F, Dumaidi K, Spiliopoulou A, Antoniadis A, Papa A. Echovirus 15 and autumn meningitis outbreak among children, Patras, Greece, 2005. J Clin Virol. 2007;40:77-79.
79. Cabrerizo M, Echevarria JE, Gonzalez I, de Miguel T, Trallero G. Molecular epidemiological study of HEV-B enteroviruses involved in the increase in meningitis cases occurred in Spain during 2006. $J$ Med Virol. 2008;80:1018-1024.

80. Trallero G, Casas I, Avellon A, Perez C, Tenorio A, De La Loma A. First epidemic of aseptic meningitis due to echovirus type 13 among Spanish children. Epidemiol Infect. 2003;130:251-256.

81. Ortner B, Huang CW, Schmid D, et al. Epidemiology of enterovirus types causing neurological disease in Austria 1999-2007: Detection of clusters of echovirus 30 and enterovirus 71 and analysis of prevalent genotypes. J Med Virol. 2009;81(2):317-324.

82. Wieczorek M, Figas A, Krzysztoszek A. Enteroviruses associated with aseptic meningitis in Poland, 2011-2014. Pol J Microbiol. 2016; 65:231-235.

83. Druyts-Voets E. Epidemiological features of entero non-poliovirus isolations in Belgium 1980-94. Epidemiol Infect. 1997;119:71-77.

84. Brunel D, Leveque N, Jacques J, Renois F, Motte J, Andreoletti L. Clinical and virological features of an aseptic meningitis outbreak in North-Eastern France, 2005. J Clin Virol. 2008;42:225-228.

85. Gm Ş, Sel K, Özkaya E, Çakir BC, Vidinlisan S, Doganci L. Enteroviral meningitis in children in Turkey. Cent Eur J Med. 2009;4:253-258.

86. Dumaidi K, Frantzidou F, Papa A, Diza E, Antoniadis A. Enterovirus meningitis in Greece from 2003-2005: diagnosis, CSF laboratory findings, and clinical manifestations. J Clin Lab Anal. 2006;20: 177-183.

87. Siafakas N, Markoulatos P, Levidiotou-Stefanou S. Molecular identification of enteroviruses responsible for an outbreak of aseptic meningitis; implications in clinical practice and epidemiology. Mol Cell Probes. 2004;18:389-398.

88. Sojka M, Wsolova L, Petrovicova A. Coxsackieviral infections involved in aseptic meningitis: a study in Slovakia from 2005 to 2009. Euro Surveill. 2011;16:19927.

89. Thoelen I, Moes E, Lemey P, et al. Analysis of the genotype and genotype correlation of VP1 and the $5^{\prime}$ noncoding region in an epidemiological survey of the human enterovirus B species. J Clin Microbiol. 2004;42(3):963-971.

90. Cordey S, Schibler M, L'Huillier AG, et al. Comparative analysis of viral shedding in pediatric and adult subjects with central nervous system-associated enterovirus infections from 2013 to 2015 in Switzerland. J Clin Virol. 2017;89:22-29.

91. Holmes CW, Koo SS, Osman $\mathrm{H}$, et al. Predominance of enterovirus $\mathrm{B}$ and echovirus 30 as cause of viral meningitis in a UK population. $J$ Clin Virol. 2016;81:90-93.

92. Atkinson PJ, Sharland M, Maguire H. Predominant enteroviral genotypes causing meningitis. Arch Dis Child. 1998;78:373-374.

93. Trallero G, Avellon A, Otero A, et al. Enteroviruses in Spain over the decade 1998-2007: virological and epidemiological studies. J Clin Virol. 2010;47(2):170-176.

94. Rudolph H, Prieto Dernbach R, Walka M, et al. Comparison of clinical and laboratory characteristics during two major paediatric meningitis outbreaks of echovirus 30 and other non-polio enteroviruses in Germany in 2008 and 2013. Eur J Clin Microbiol Infect Dis. 2017;36 (9):1651-1660.

95. Berlin LE, Rorabaugh ML, Heldrich F, Roberts K, Doran T, Modlin JF. Aseptic meningitis in infants $<2$ years of age: diagnosis and etiology. $J$ Infect Dis. 1993;168:888-892.

96. Julian KG, Mullins JA, Olin A, et al. Aseptic meningitis epidemic during a West Nile virus avian epizootic. Emerg Infect Dis. 2003;9(9): 1082-1088.

97. Dagan R, Jenista JA, Menegus MA. Association of clinical presentation, laboratory findings, and virus genotypes with the presence of meningitis in hospitalized infants with enterovirus infection. $J$ Pediatr. 1988;113:975-978. 
98. Karzon DT, Hayner NS, Winkelstein W Jr, Barron AL. An epidemic of aseptic meningitis syndrome due to $\mathrm{ECHO}$ virus type 6. II. A clinical study of ECHO 6 infection. Pediatrics. 1962;29:418-431.

99. Peci A, Winter AL, Eshaghi A, et al. Coxsackieviruses in ontario, january 2005 to december 2011. Int J Infect Dis. 2014;25:136-141.

100. Luchs A, Russo DH, Cilli A, et al. Echovirus 6 associated to aseptic meningitis outbreak, in Sao Joaquim da Barra, Sao Paulo, Brazil. Braz J Microbiol. 2008;39(1):28-31.

101. Kumar A, Shukla D, Kumar R, et al. Molecular identification of enteroviruses associated with aseptic meningitis in children from India. Arch Virol. 2013;158(1):211-215.

102. Lee ST, Ki CS, Lee NY. Molecular characterization of enteroviruses isolated from patients with aseptic meningitis in Korea, 2005. Arch Virol. 2007;152:963-970.

103. Kim HJ, Kang B, Hwang S, Hong J, Kim K, Cheon DS. Epidemics of viral meningitis caused by echovirus 6 and 30 in Korea in 2008. Virol J. 2012;9:38.

104. Joo CH, Ahn J, Seo I, et al. Characterization of nonpolio enteroviruses recovered from patients with aseptic meningitis in Korea. Intervirology. 2005;48(2-3):97-103.

105. Baek K, Yeo S, Lee B, et al. Epidemics of enterovirus infection in Chungnam Korea, 2008 and 2009. Virol J. 2011;8(1):297.

106. Hyeon JY, Hwang S, Kim H, et al. Accuracy of diagnostic methods and surveillance sensitivity for human enterovirus, South Korea, 1999-2011. Emerg Infect Dis. 2013;19(8):1268-1275.

107. Momoki ST. Surveillance of enterovirus infections in Yokohama city from 2004 to 2008. Jpn J Infect Dis. 2009;62:471-473.

108. Cui A, Yu D, Zhu Z, et al. An outbreak of aseptic meningitis caused by coxsackievirus A9 in Gansu, the People's Republic of China. Virol J. 2010;7(1):72.

109. Liu N, Jia L, Yin J, et al. An outbreak of aseptic meningitis caused by a distinct lineage of coxsackievirus B5 in China. Int J Infect Dis. 2014;23:101-104.

110. Kao CH, Lee SS, Liu YC, et al. Outbreak of aseptic meningitis among adults in southern Taiwan. J Microbiol Immunol Infect. 2003;367: 192-196.

111. Zhu $Y$, Zhou X, Liu J, et al. Molecular identification of human enteroviruses associated with aseptic meningitis in Yunnan province, Southwest China. Springerplus. 2016;5(1):1515.

112. Xiao H, Guan D, Chen R, et al. Molecular characterization of echovirus 30 -associated outbreak of aseptic meningitis in Guangdong in 2012. Virol J. 2013;10(1):263.

113. Tao Z, Wang H, Li Y, et al. Molecular epidemiology of human enterovirus associated with aseptic meningitis in Shandong Province, China, 2006-2012. PLoS ONE. 2014;9(2):e89766.

114. Kaida A, Kubo H, Iritani N, Murakami T, Haruki K. Isolation of Echovirus type 13 in Osaka City during 2001-2002. Jpn J Infect Dis. 2004;57:127-128.

115. Hsu CH, Lu CY, Shao PL, et al. Epidemiologic and clinical features of non-polio enteroviral infections in northern Taiwan in 2008. J Microbiol Immunol Infect. 2011;44(4):265-273.

116. Chen $\mathrm{P}$, Tao Z, Song $\mathrm{Y}$, et al. A coxsackievirus B5-associated aseptic meningitis outbreak in Shandong Province, China in 2009. J Med Virol. 2013;85(3):483-489.

117. Zhao YN, Jiang QW, Jiang RJ, Chen L, Perlin DS. Echovirus 30, Jiangsu Province, China. Emerg Infect Dis. 2005;11:562-567.

118. Huang QS, Carr JM, Nix WA, et al. An echovirus type 33 winter outbreak in New Zealand. Clin Infect Dis. 2003;37(5):650-657.

119. Papadakis G, Chibo D, Druce J, Catton M, Birch C. Detection and genotyping of enteroviruses in cerebrospinal fluid in patients in Victoria, Australia, 2007-2013. J Med Virol. 2014;86:1609-1613.

120. WebPlotDigitizer [computer program]. Version 4.1. Austin, Texas, USA2018.

121. Group OLoEW. The Oxford Levels of Evidence 2. 2011. https: //www.cebm.net/index.aspx?o=5653. Accessed 2nd March 2019.
122. Nyaga VN, Arbyn M, Aerts M. Metaprop: a Stata command to perform meta-analysis of binomial data. Arch Public Health. 2014;72 (1):39.

123. Freeman MF, Tukey JW. Transformations related to the angular and the square root. Ann Stat. 1950;21:607-611.

124. Mittlböck M, Heinzl H. A simulation study comparing properties of heterogeneity measures in meta-analyses. Stat Med. 2006;25:43214333.

125. DerSimonian R, Laird N. Meta-analysis in clinical trials. Control Clin Trials. 1986;7:177-188.

126. Cassidy H, Poelman R, Knoester M, van Leer-Buter CC, Niesters HGM. Enterovirus D68- The New Polio? Front Microbiol. 2018;9: 2677.

127. McKay SL, Lee AD, Lopez AS, et al. Increase in acute flaccid myelitis-United States, 2018. MMWR Morb Mortal Wkly Rep. 2018; 67(45):1273-1275.

128. Messacar K, Asturias EJ, Hixon AM, et al. Enterovirus D68 and acute flaccid myelitis-evaluating the evidence for causality. Lancet Infect Dis. 2018;18(8):e239-e247.

129. Hixon AM, Yu G, Leser JS, et al. A mouse model of paralytic myelitis caused by enterovirus D68. PLoS Pathog. 2017;13(2):e1006199.

130. Huebner RJ. Criteria for etiologic association of prevalent viruses with prevalent diseases: the virologists dilemma. Ann N Y Acad Sci. 1957;67:430-438.

131. Fredricks DN, Relman DA. Sequence-based identification of microbial pathogens: a reconsideration of Koch's postulates. Clin Microbiol Rev. 1996;9(1):18-33.

132. Centre for Disease Control and Prevention. Acute flaccid myelitis, Specimen Collection Instructions 2018. https://www.cdc.gov/acuteflaccid-myelitis/hcp/instructions.html. Accessed 5th June 2019.

133. Fowlkes AL, Honarmand S, Glaser C, et al. Enterovirus-associated encephalitis in the California encephalitis project, 1998-2005. J Infect Dis. 2008;198(11):1685-1691.

134. Wang Y, Yu C. Animal models of enterovirus 71 infection: applications and limitations. J Biomed Sci. 2014;21:31.

135. Ke Y, Liu WN, Her Z, et al. Enterovirus A71 Infection activates human immune responses and induces pathological changes in humanized mice. J Virol. 2019;93:e01066-e01018.

136. BernitE, de Lamballerie $X$, Zandotti $C$, et al. Prospective investigation of a large outbreak of meningitis due to echovirus 30 during summer 2000 in marseilles, france. Medicine (Baltimore). 2004;83(4):245-253.

137. Chiang PS, Huang ML, Luo ST, Lin TY, Tsao KC, Lee MS. Comparing molecular methods for early detection and serotyping of enteroviruses in throat swabs of pediatric patients. Plos One. 2012;7(10): e48269.

138. Yoke-Fun C, AbuBakar S. Phylogenetic evidence for inter-typic recombination in the emergence of human enterovirus 71 subgenotypes. BMC Microbiol. 2006;6(1):74.

\section{SUPPORTING INFORMATION}

Additional supporting information may be found online in the Supporting Information section at the end of this article.

How to cite this article: Suresh S, Rawlinson WD, Andrews PI, Stelzer-Braid S. Global epidemiology of nonpolio enteroviruses causing severe neurological complications: A systematic review and meta-analysis. Rev Med Virol. 2020;30:e2082. https://doi.org/10.1002/rmv.2082 